Article

\title{
Model Hyetographs of Short-Term Rainfall for Wroctaw in the Perspective of 2050
}

\author{
Katarzyna Wartalska *(D) and Andrzej Kotowski
}

Department of Water Supply and Sewerage Systems, Faculty of Environmental Engineering, Wroclaw University of Science and Technology, 50-370 Wroclaw, Poland; andrzej.kotowski@pwr.edu.pl

* Correspondence: katarzyna.wartalska@pwr.edu.pl

Received: 24 April 2020; Accepted: 19 June 2020; Published: 21 June 2020

\begin{abstract}
One of the most important problems while modeling stormwater drainage systems is the choice of rainfall scenario, which will take into account the real rainfall distribution over time. This problem is particularly significant due to the climate change observed in recent decades, manifested, among others, in the increase in the precipitation intensities or changes in their structure. Taking into account these forecasts is essential to safely design sewer systems and their proper operation. The work aims to verify the Euler type II standard rainfall used so far to model sewage systems in Poland and to develop the forecasted form of this pattern in the perspective of 2050. Precipitation data from measurement stations in Wrocław were used as research material. The prediction model of maximum rainfall amounts allowed to determine the forecasted increase in intensities of short-term rainfall (for the occurrence frequencies recommended by Standard EN 752:2017 for the dimensioning and modeling of sewage systems). On this basis, model hyetographs forecasted for 2050 were prepared for Wrocław. Their choice-as a future rainfall load in hydrodynamic modeling - will allow one to meet the requirements for the frequency of flooding occurrence from sewer systems and their safe operation over several decades.
\end{abstract}

Keywords: rainfall hyetographs; climate change; rainfall models; short-term rainfall; rainfall distribution; stormwater drainage system modeling

\section{Introduction}

Climate changes are observed in Poland, as in other countries in Europe, and in the world. They are manifested by, among others, increases in air temperature and the occurrence frequency of extreme events, such as flash floods or urban floods [1]. The cause of warming is not fully recognized and is still controversial. Undoubtedly, the observed increase in air temperature significantly affects the circulation of water in the hydrological cycle (evaporation-condensation-precipitation). According to the report of the Intergovernmental Panel on Climate Change (IPCC), in the period 1960-2005, there was an increase in the average annual temperature of the globe by $0.74{ }^{\circ} \mathrm{C}$. As a result, the level of seas and oceans increased by an average $0.19 \mathrm{~m}$ over the years 1901-2010 [2]. According to projections based on the global climate model, in the current century, air temperature may rise by 1.7 to even $4.4{ }^{\circ} \mathrm{C}$, and for each degree of the temperature increase, a global increase in precipitation intensity by about $7 \%$ is predicted [3].

The random nature of precipitation makes it impossible to achieve the fully reliable operation of urban drainage systems, both now and in the future. Potential environmental threats caused by outflows from stormwater drainage channels can be demonstrated by hydrodynamic modelling. Simulation models (SWMM type) allow us, among others, to apply precipitation scenarios that change over time and space. These scenarios can be intense local precipitation measured over many years, which are, however, difficult to access, as well as model precipitation. The concept of "model precipitation" 
determines the load of the basin by precipitation, with the course normalized in time. Normalization is based on a statistical analysis of heavy precipitation events recorded in the past and reflects their most frequently recurring courses in time [4]. For example, in Germany, Euler type II model rainfall is used to simulate short-term precipitation-in accordance with DWA-A118:2006. This pattern was also recommended in Poland [5], presuming that Polish climatic conditions are similar to German (a transition zone between the maritime and continental climates). Euler type II model rainfall is dimensional, and based on the assumption that the largest momentary (for time interval $\Delta t=5 \mathrm{~min}$ ) intensity of precipitation occurs at the end of the first, one-third part of its duration $(t \in(0,0.33] T)$. Local DDF (depth duration frequency) curves, or IDF (intensity duration frequency) curves are used to create it, for the assumed exceedance probabilities $(p)$, i.e., interchangeable precipitation occurrence frequencies $(C=1 / p)$ (which is interpreted as: 1 time per $C$ years), according to the recommendations of standard EN 752:2017. This standard distinguishes the permissible frequency of channel outflows in a seven-degree scale of environmental impact (for example defined locations of areas), within the scope of: $p \in[100,2] \%$, i.e., respectively: $C \in[1,50]$ years (the sewer systems design criteria for sewer flooding threats, according to EN 752 from 2017, are given in Supplementary Material).

Today, the required standard of drainage of urbanized areas is defined as the adaptation of the sewage system to accept the maximum (forecast) rainwater streams, with a frequency equal to the permissible (socially acceptable) frequency of outflow to the surface of the land. It should be emphasized that with today's dimensioning of newly built sewage systems or modernization of existing systems, it is necessary to take the forecast effects of climate change in the period of 2050-2100 into account [6-10]. The identification of future (potential) system overloads justifies the need to take appropriate remedial actions today, consisting in e.g., the construction of relief channels, retention and infiltration tanks or embankments [11].

Modeling the reliability of stormwater drainage, recommended by standard EN 752, is rarely used in Poland, among others, due to the lack of reliable precipitation models. This paper is part of the trend to improve the basics of hydrodynamic modelling of land drainage systems on the example of Wrocław-as presented in monographs [1,5]. In particular, in this paper, the model Euler type II hyetograph, previously used to model sewage networks, was verified, and the forecast form of this model was developed in the perspective of 2050.

\section{Study Area and Data Used}

Wrocław is a city located in southwestern Poland, in the Silesian Lowland, on the Odra River and its four tributaries. The research material came from the measurement station of the Polish Institute of Meteorology and Water Management (IMGW) in Wrocław and the local precipitation monitoring network of the Municipal Water and Sewage Company (MPWiK) in Wrocław. Precipitation monitoring stations are located at the altitude of approx. 120 masl, over the area of approx. $300 \mathrm{~km}^{2}$ (Figure 1). The list of rain gauges with detailed geographical location is presented in Table 1.

Precipitation records with high temporal resolution $(1 \mathrm{~min})$ were used to investigate the hyetographs' shapes; for IMGW stations-for a period of 12 years (2007-2018), and for 11 stations of local monitoring network of MPWiK-for a period of one to several years (2012-2018). The precipitation data selected for the analyses can be considered representative of hydrological conditions of the central lowland part of Poland.

To separate independent precipitation phenomena, our own methodology of analysis of intervals between precipitation events (MDPD) was used [5]. Independent precipitation events were assigned the occurrence frequency $(C)$, based on the current maximum precipitation model for Wrocław. From a set of 951 hyetographs, precipitation events with exceedance frequencies $C(t) \geq 1$ year were selected for statistical analysis, obtaining a sample of 126 precipitation events.

For statistical analyses of the similarity of the real hyetographs' shapes in relation to the Euler type II model, selected precipitation events were assigned to 3 groups: $t \leq 120 \mathrm{~min}$-short duration precipitation, $t \in(120,720) \mathrm{min}-$ medium duration precipitation and $t>720 \mathrm{~min}$-long duration 
precipitation. In Wrocław, analyzed precipitation events have mostly short durations-75 events out of $126(59 \%)$. Medium and long duration precipitation events have a smaller share- 51 events ( $21 \%$ for precipitation events with $t \in(120,720) \mathrm{min}$ and $20 \%$ with $t>720 \mathrm{~min})$.

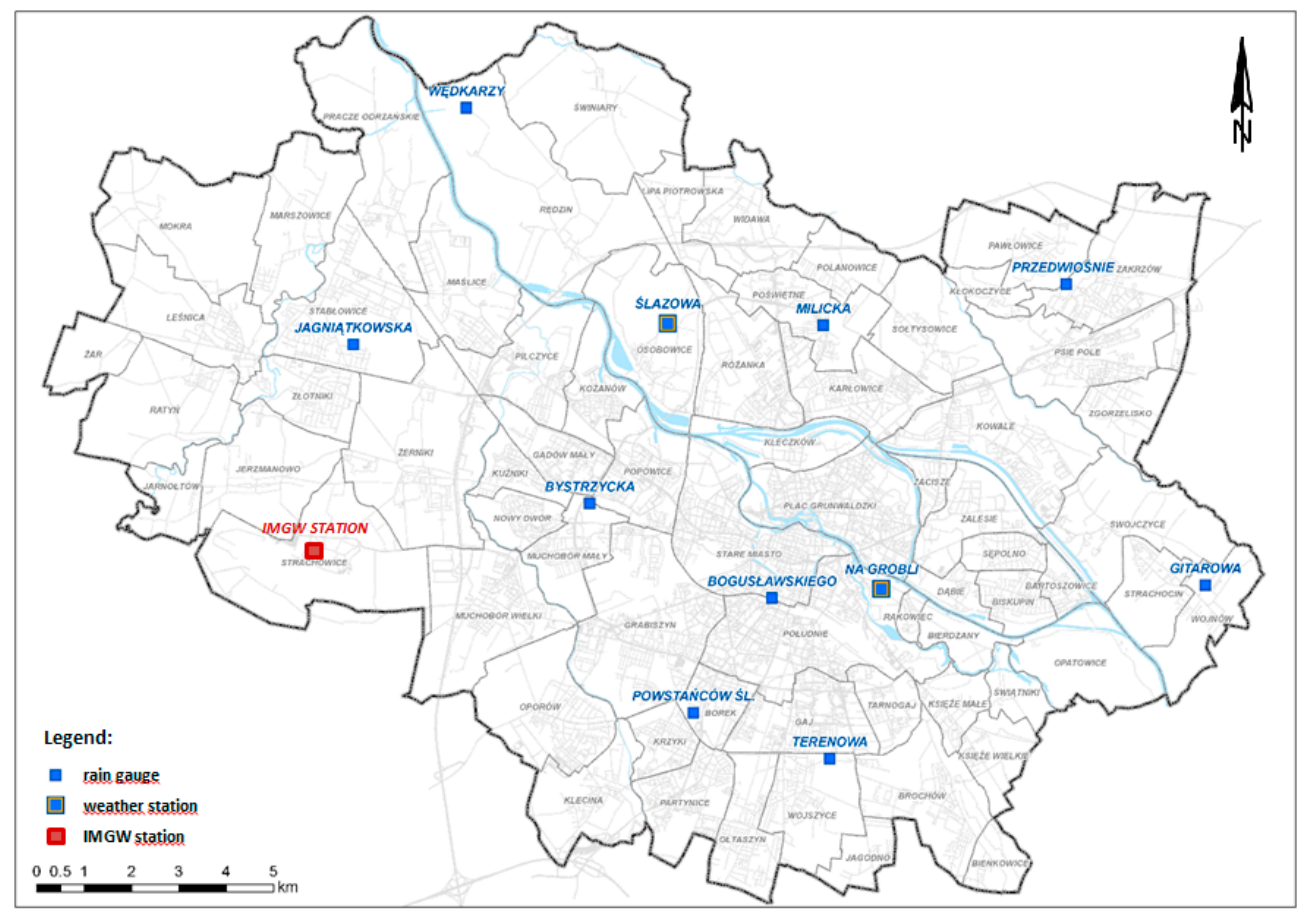

Figure 1. Location of measuring stations in Wrocław (red-Polish Institute of Meteorology and Water Management (IMGW) station; blue-Municipal Water and Sewage Company (MPWiK) stations—rain gauges and weather stations).

Table 1. Location of rainfall measuring stations in Wrocław.

\begin{tabular}{cccc}
\hline \multirow{2}{*}{ Name of Rain Gauge } & \multicolumn{3}{c}{ Location } \\
\cline { 2 - 4 } & Longitude & Latitude & Altitude (masl) \\
\hline IMGW STATION & $16.90^{\circ} \mathrm{E}$ & $51.10^{\circ} \mathrm{N}$ & 120 \\
BOGUSŁAWSKIEGO & $17.03^{\circ} \mathrm{E}$ & $51.10^{\circ} \mathrm{N}$ & 117 \\
BYSTRZYCKA & $16.97^{\circ} \mathrm{E}$ & $51.12^{\circ} \mathrm{N}$ & 120 \\
PRZEDWIOŚNIE & $17.11^{\circ} \mathrm{E}$ & $51.16^{\circ} \mathrm{N}$ & 119 \\
GITAROWA & $17.16^{\circ} \mathrm{E}$ & $51.11^{\circ} \mathrm{N}$ & 118 \\
NA GROBLI & $17.06^{\circ} \mathrm{E}$ & $51.10^{\circ} \mathrm{N}$ & 123 \\
JAGNIATKOWSKA & $16.90^{\circ} \mathrm{E}$ & $51.15^{\circ} \mathrm{N}$ & 116 \\
MILICKA & $17.04^{\circ} \mathrm{E}$ & $51.15^{\circ} \mathrm{N}$ & 119 \\
POWSTAŃCOW ŚLASKICH & $17.02^{\circ} \mathrm{E}$ & $51.09^{\circ} \mathrm{N}$ & 122 \\
ŚLAZOWA & $17.00^{\circ} \mathrm{E}$ & $51.15^{\circ} \mathrm{N}$ & 116 \\
TERENOWA & $17.05^{\circ} \mathrm{E}$ & $51.07^{\circ} \mathrm{N}$ & 121 \\
WEZDKARZY & $16.95^{\circ} \mathrm{E}$ & $51.18^{\circ} \mathrm{N}$ & 116 \\
\hline
\end{tabular}

\section{Method of Analysis}

Many methods for creating model hyetographs are described in the literature. Their division is presented among others in papers [12-15]. These methods can be divided into 3 groups: methods based on IDF/DDF curves, methods based on historical precipitation data and stochastic methods-still being in the experimental phase. The oldest of the methods based on IDF/DDF curves is the Keifer and Chu method [16]. Model hyetographs based on historical precipitation records are created by the statistical analysis of the selected precipitation phenomena. They are usually presented in the form of a cumulative hyetographs, i.e., as dimensionless mass curves. The oldest is the method by Huff [17], 
who proposed the division of precipitation events into 4 groups, called quartiles-determining in which part of the precipitation duration its maximum intensity occurred. Based on this, he created the so-called quartile charts, illustrating changes in precipitation over time. Huff curves are a probabilistic representation of the ratio of cumulative precipitation amounts to the corresponding cumulative duration, in the form of the so-called probability isopleths. Huff curves became broadly applicable for analyzing precipitation variability, including in papers [5,18-22]. In this paper, this method is also used as one of the methods of grouping precipitation for analysis.

For grouping precipitation according to the similarity of hyetograph physical characteristics-i.e., for qualitative analyses, known methods can be used, e.g., cluster analysis using the Ward method or $k$-means method $[5,23]$. The Ward method belongs to hierarchical methods. The measure of similarity is the function of the distance between bonds of object pairs. Most often it is the Euclidean distance, forming the so-called dendrogram of clusters of objects with similar characteristics. The $k$-means method, however, belongs to non-hierarchical methods. It consists of dividing the investigated sample into a projected number of ( $k$ ) clusters (initially indicated, e.g., by the Ward method). Both methods, as well as the Huff curves, became applicable in the presented research-in order to verify which of the precipitation grouping, due to the similarity of shapes, best illustrates the typical courses of temporal distribution of short-term precipitation.

Quantitatively, hyetographs can be characterized by the (geometrical) indicator of the peak location of the highest intensity $-r$, mass indicator $-m_{33}$ determining the ratio of the accumulated amount (mass) of rainfall for $1 / 3$ of the initial rainfall duration to the total amount, and the intensity unevenness over time indicator $-n_{I}$, respectively [5]:

$$
\begin{gathered}
r=\frac{t_{\text {peak }}\left(h_{\max }(\Delta t)\right)}{T} \\
m_{33}=\sum_{0}^{0.33 T} h_{i} / P_{c}(T) \\
n_{I}=\frac{I_{\max }(\Delta t)}{I_{m}(T)}
\end{gathered}
$$

where: $t_{\text {peak }}\left(h_{\max }(\Delta t)\right)$ —occurrence time of the peak of maximum interval rainfall amount, min; $T$ — total duration of rainfall, $\mathrm{min}, h_{i}$-temporary amount of rainfall (for $\Delta t=1 \mathrm{~min}$ ), $\mathrm{mm} ; P_{c}(T)$-total amount of rainfall (in time $T$ ), $\mathrm{mm} ; I_{\max }(\Delta t)$-maximum interval $(\Delta t)$ rainfall intensity, $\mathrm{mm} / \mathrm{min} ; I_{m}(T)$-mean rainfall intensity (in time $T$ ), $\mathrm{mm} / \mathrm{min}$.

In monograph [1], Kaźmierczak analyzed the changes in maximum rainfall amounts in Wrocław. Based on pluviographic records from the IMGW-PIB station in Wrocław from 59 years (1960-2018), he developed a predictive model for the maximum rainfall amount for Wrocław. He separated thirty-year periods from the measuring material: 1960-1989, 1961-1990, .. , 1989-2018. The resulting 30 measurement series formed the basis for developing probability models of maximum rainfall. The maximum rainfall for statistical analysis was selected by the peak over threshold method-for 16 durations recommended for formulating rainfall models, i.e., 5, 10, 15, 30, 45, 60, 90, 120, 180, 360, 720, 1080, 1440, 2160, 2880 and $4320 \mathrm{~min}$. As a result, 2018 rainfall was selected for analysis, from which 30 largest rainfall amounts (for each of the 16 rainfall durations) were chosen for each of the 30 periods (from 1960-1989 to 1989-2018) and ranked non-growing. The data prepared in this way was assigned the empirical probability of exceedance. Then, the estimators of the GED (generalized exponential distribution) and Weibull distribution parameters (as the best to describe the maximum rainfall in Polish conditions were demonstrated, among others in [24-26]) were determined by the maximum likelihood method, through which maximum rainfall for each of the 30 analyzed periods was described.

The conformity of theoretical distributions with measured data can be examined using the $\lambda$-Kolmogorow test for statistics [27]:

$$
\lambda=D_{\max } \sqrt{N}
$$


where: $D_{\max }=\max |p(m, N)-p| ; p(m, N)$-empirical probability:

$$
p(m, N)=\frac{m}{N+1}
$$

where: $m$-the place of the word in the non-growing order of precipitation; $N$-random sample size.

The null hypothesis about the compatibility of distributions is adopted when the measurement data match the considered distribution at a given significance level (usually 95\%) - test statistics are less than the critical value $\lambda_{k r}$. The alternative hypothesis, about the non-compliance of the distributions with the measured data, is adopted otherwise. The best one should be chosen from the schedules meeting the selected compliance test. Information criteria are used to assess distributions [28,29], i.e., the Bayesian Schwartz information criterion:

$$
\mathrm{BIC}=-2 \ln L+k \ln N
$$

where: $k$-number of estimated parameters.

The criteria consist of two parts. The first describes the measure of fit of the model, while the second defines its simplicity. Therefore, information criteria allow one to choose models that are well matched, and at the same time as simple as possible. The model for which the information criterion obtains the lowest value is considered to be the best.

The non-parametric Mann-Kendall test was used to detect trends in the changes in the precipitation time series [30,31]. This test answers the question as to whether the values measured in the time series have a tendency to gradually increase or decrease. The rate of the change of analyzed trend in time can be described by the directional coefficient of the straight line expressed by Sen's slope estimator. Changes (increases or decreases) at a significance level $\alpha<0.05$ are considered statistically significant.

The applied Mann-Kendall test showed statistically significant trends of changes in equation parameters, describing the dependence of scale and the lower limit parameters estimators (in the years from 1960-1989 to 1989-2018) on the duration of precipitation. As a result, equations were obtained which, after substitution to the GED quantile, enabled the formulation of a predictive model of the maximum precipitation amount (7), in the form:

$$
h_{\max }(t, p, y)=\left(-40.81+2.27 \times 10^{-2} y\right) t^{1.96-8.33 \times 10^{-4} y}-\frac{\ln \left(1-(1-p)^{1 / 0.737}\right)}{\left(-3.34+1.83 \times 10^{-3} y\right)\left(t-66.4+3.09 \times 10^{-2} y\right)^{-0.25}}
$$

dependent on: duration (from $t=5$ to $t=4320 \mathrm{~min}$ ), exceedance probability (from $p=0.02$ to $p=1$ ) and year, per which precipitation is measured (from $y=1989$ to $y=2050$ ).

Research carried out by Kaźmierczak showed that in the perspective of 2050, an increase in short duration precipitation and a decrease in the amount of precipitation with longer duration are forecasted in Wrocław [1]. In particular, short-term rainfall amounts will increase by $6-10 \%$-depending on the frequency of occurrence $C$ and the duration of precipitation $t$ (the largest projected increases were noted for $t=5 \mathrm{~min}$ ), which will result in an increase of their frequency of occurrence by about $30 \%$ in the future. For example, precipitation occurring currently once every $C=3$ years will occur once every $C=2$ years in the perspective of 2050. This means that more frequently, we will observe local flooding caused, especially by high intensity short-term precipitation.

\section{Results and Discussion}

\subsection{Verification of the Euler Type II Model}

Three research methods were used for qualitative analyses, i.e., for grouping precipitation according to the similarity of the hyetographs' shape: the Huff method, cluster analysis with the Ward, and $k$-means methods. The results of rainfall grouping with these methods allowed choosing the best of them. The Huff method did not allow the determination of clear "patterns" of the analyzed 
hyetographs depending on the duration of precipitation. The shapes of dimensionless hyetographs in the form of mass curves turned out to be quite irregular in Huff's quartile groups, and the intensity peaks were at a similar median level. The results of precipitation grouping using the Ward method showed the existence of four, significantly different precipitation clusters, i.e., with similar courses of mass curves within four groups. Figure 2 presents the dendrogram of precipitation grouping with the use of the Ward method (the cut-off level of approx. 3 enabled the division of the rainfall sample to 4 clusters).

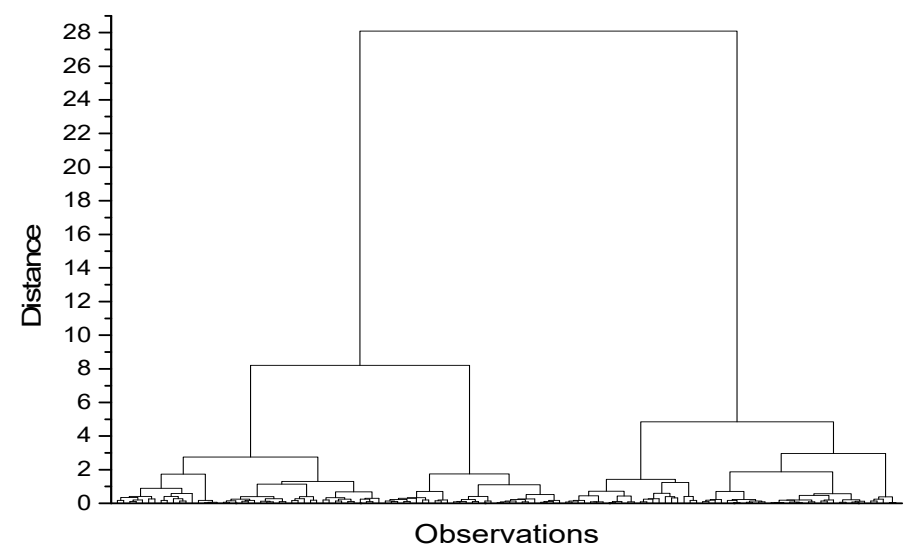

Figure 2. Dendrogram of precipitation grouping using the Ward method for Wrocław [5].

This enabled the use of another precipitation grouping method-the $k$-means method. The $k$-means method (for $k=4$ according to Ward) proved to be the most useful for precipitation selection according to its genetic characteristics. As a result of the precipitation grouping by the $k$-means method, the most expressive clusters were obtained. This paper is limited to presenting the results of precipitation grouping by the $k$-mean method. Figure 3 illustrates the total precipitation curves in 4 clusters separated by this method with plotted median curves. It can be seen that the bundles of most precipitation sum curves are located close to the respective medians in the four analyzed clusters.

The results of the qualitative grouping of precipitation allow us to state that almost a half-62 precipitation events ( $49 \%$ of the sample) have a peak of accumulated amounts located at $1 / 3$ of the initial duration (in clusters no. 3 and 4), during which the majority of the total precipitation mass is deposited. Clusters 3 and 4 include the majority (48 of 75) of short duration rainfall events and 3 medium duration events-from the border of short and medium duration precipitation, i.e., $T<150$ min. Physically indicated short-term precipitation events (51) were subjected to a detailed quantitative analysis of the similarity of hyetographs' shapes to the Euler type II model.

Figure 4 presents the sum curves of 51 analyzed precipitation events together with the calculated median curve, which shows that at $1 / 3$ of their initial duration, the precipitation mass reaches approx. $75 \%$.

In Figure 5, a dimensionless hyetograph for the investigated 51 precipitation events was drawn. It depicts the $50 \%$ percentile (median) curve. This hyetograph illustrates ranges of measured relative interval values $(\Delta t=0.1 T)$ of rainfall amounts $\left(h_{i} / P_{c}\right)$, using the so-called box charts. Box charts allow the pictogram to include information about the location, dispersion and shape of the empirical distribution of the investigated precipitation sample. The so-called whiskers were limited to $10 \%$ and $90 \%$ of the percentile of the data set, which are identified in the literature $[17,22]$, with confidence intervals (at 10\% and 90\% respectively). According to the graph, the peak position indicator is set to $r=0.2 t_{i} / T$, i.e., at $1 / 5$ of the rainfall duration.

The initial analysis allows us to state that the features of mass distribution on dimensionless hyetographs of 51 investigated precipitation events are similar to the Euler type II model. However, this observation requires confirmation in a detailed quantitative assessment of the similarity of the dimensional hyetographs' shapes of these precipitation events. To assess the quantitative similarity of the 
local hyetographs' shapes, three indicators were used to characterize: location of the maximum amount peak (1) mass distribution (2) and unevenness in rain intensity in time (3) - in dimensional systems.

The Euler type II model precipitation was developed from IDF curves for Wrocław, for the purposes of comparative analyses. The current maximum precipitation model (DDF forms) for Wrocław was used to create IDF curves [1]. Based on this, 28 Euler models for Wrocław were created: for 7 durations: $T \in\{30,45,60,75,90,120,150\}$ min (divided into three and five equal parts) and four occurrence frequency classes: $C \in\{1,2,5,10\}$ years.

Mass distribution and unevenness during precipitation events were investigated in the created models. Values of index $m_{33}$ turned out to be almost identical, regardless of $T$ and $C$. The average value of indicator $m_{33}$ is 0.741 . Unevenness during intensity varies from 3.64 to 12.24 -depending on the duration of precipitation events $(T=30-150 \mathrm{~min})$, but it is independent of their frequency $(C)$. The average value of indicator $n_{I}=7.71$.

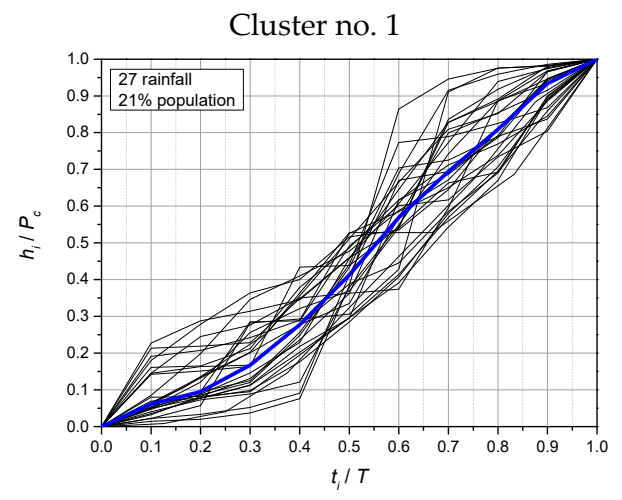

Cluster no. 3

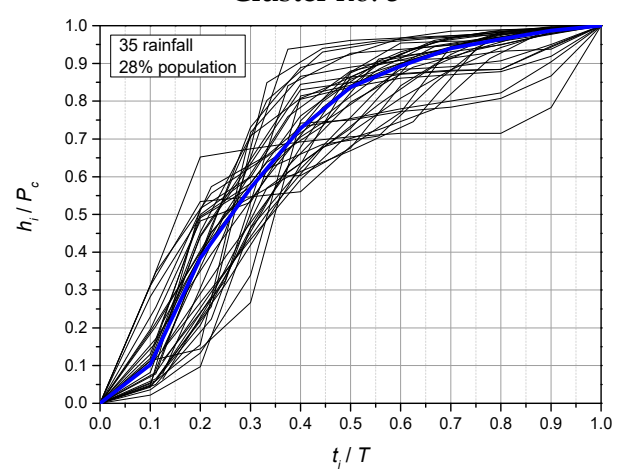

Cluster no. 2

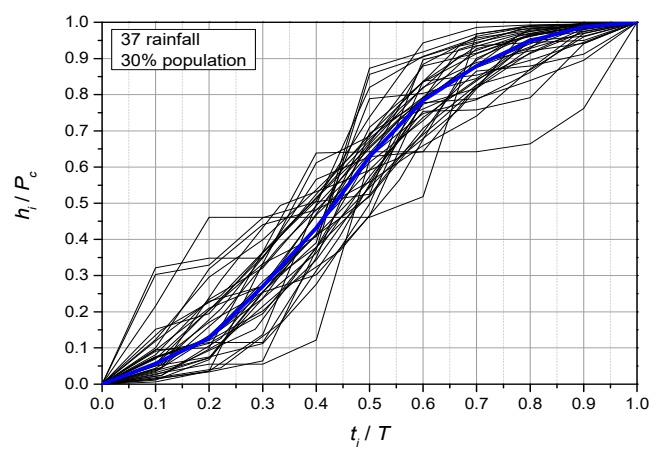

Cluster no. 4

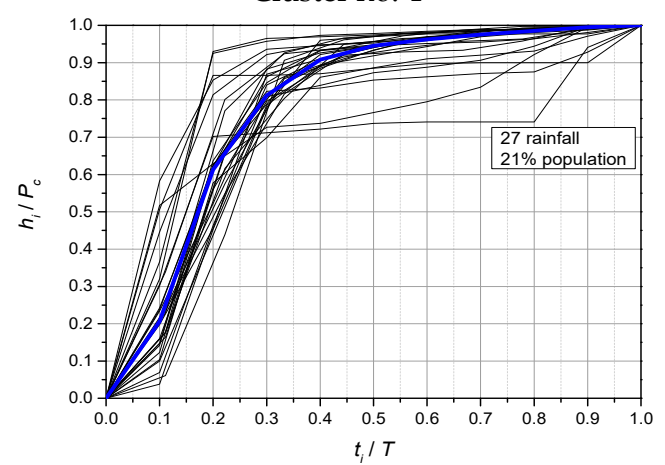

Figure 3. Mass rainfall curves with the median in four clusters separated by $k$-means method for Wrocław.

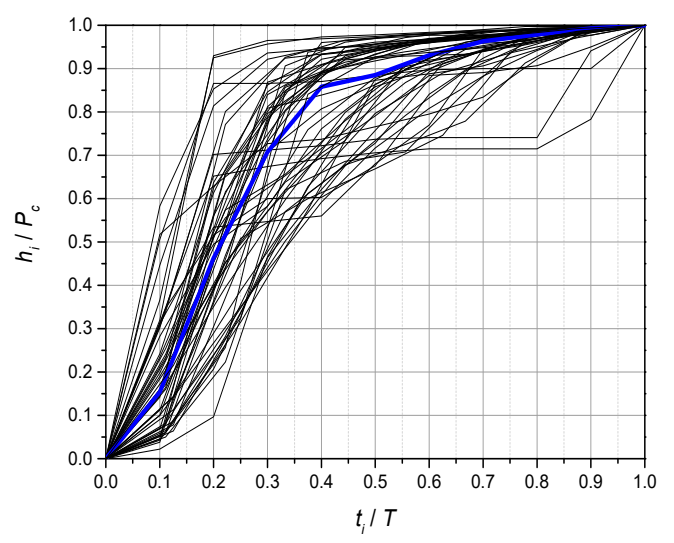

Figure 4. Mass curves for 51 short duration rainfall with the median for Wrocław. 


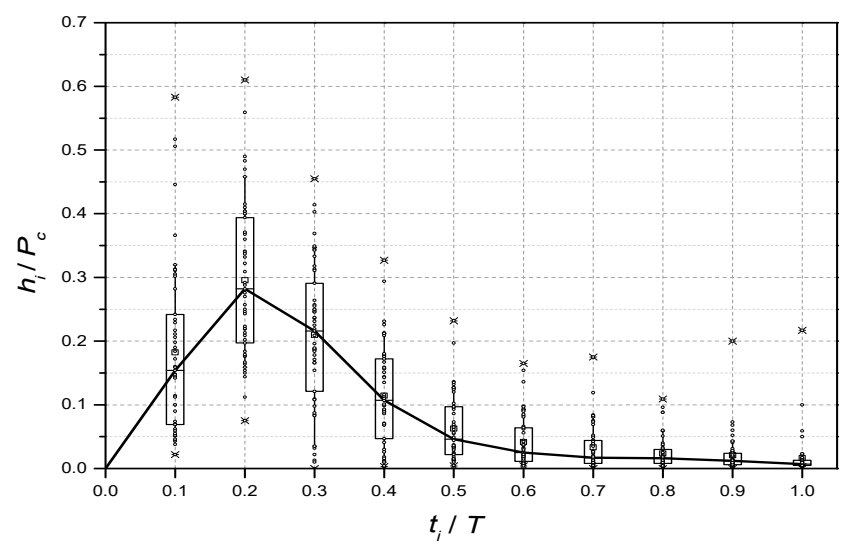

Figure 5. Dimensionless hyetograph of interval increments of 51 precipitation, with box charts of measurement results for Wrocław.

The parameters of 28 Euler type II precipitation models determined for Wrocław data regarding mass distribution and unevenness in time were then compared with parameters of the real rainfall hyetographs. To maintain the correctness of comparisons, i.e., to meet the condition of divisibility of the rainfall duration into three equal parts, and at the same time, its divisibility into intervals $\Delta t=5 \mathrm{~min}$, the real duration of precipitation events $T$ was corrected to their model duration $T^{\prime}$ (to not lose the mass of rainfall: $T^{\prime} \geq T$ ). For quantitative assessments, the following indicators were re-used: $r, m_{33}$ and $n_{I}$-in relation to time $T^{\prime}$ (Table 2).

Table 2. Summary of mass distribution and unevenness in time parameters for real and Euler type II model rainfall.

\begin{tabular}{ccccc}
\hline \multirow{2}{*}{ Indicator } & \multicolumn{2}{c}{ Real Rainfall (for Duration $T^{\prime}$ ) } & \multicolumn{2}{c}{ Euler Type II Rainfall Models } \\
\cline { 2 - 5 } & Range & Mean & Range & Mean \\
\hline$r$ & $0.02-0.29$ & 0.15 & $0.25-0.32$ & 0.285 \\
$m_{33}$ & $0.53-0.96$ & 0.80 & $0.736-0.749$ & 0.741 \\
$n_{I}$ & $1.59-10.26$ & 4.09 & $3.65-12.24$ & 7.42 \\
\hline
\end{tabular}

For peak position indicator $r$, the values for 51 real precipitation events differ in terms of interval location in relation to 28 models. Similarly, the average value of mass distribution index $m_{33}{ }^{\prime}=0.80$ on 51 dimensional hyetographs is higher than the constant value $m_{33}=0.741$ for 28 Euler type II models. In both cases, however, both the interval intensity peak and the main precipitation mass are located in the first $1 / 3$ part of the duration. Precipitation unevenness in time on 51 hyetographs was significant: $n_{I}{ }^{\prime} \in[1.59,10.26]$. In Euler type II model precipitation, the unevenness is at a similar level $n_{I} \in$ [3.64, 12.24]. These values can be considered similar. The discrepancies between the mean values fall into the accuracy class of hydrological measurements and calculations related to random phenomena.

The analysis of real precipitation events recorded in Wrocław allows us to conclude that the Euler type II model largely reflects the investigated short duration rainfall (for $T<150 \mathrm{~min}$ ). The main mass of precipitation occurs in the first $1 / 3$ part of the rainfall duration. However, the location of the maximum interval intensity peak $(\Delta t=5 \mathrm{~min}$ ) varies significantly-for the investigated precipitation events, it occurs at the end of $1 / 5$ part of their duration, and in Euler type II models, it occurs at the end of $1 / 3$ of this time. Therefore, to generalize the research results, it is necessary to correct the position of the maximum interval intensity peak-from $1 / 3 \mathrm{~T}$ to $1 / 5 \mathrm{~T}$.

\subsection{Examples of Short Duration Rainfall Models for 2050}

Table 3 lists the maximum precipitation amounts calculated from the predictive model (4) within the range $t \in[5,75]$ min and $C \in\{1,2,3,5,10,30,50\}$ years, based on which IDF curves for Wrocław for 2050 were developed. 
Table 3. Forecasted maximum rainfall amounts $\left(h_{\max }, \mathrm{mm}\right)$ in Wrocław in 2050.

\begin{tabular}{cccccccc}
\hline $\boldsymbol{t}$, $\mathbf{m i n}$ & $\boldsymbol{C = \mathbf { 1 }}$ & $\boldsymbol{C = \mathbf { 2 }}$ & $\boldsymbol{C = 3}$ & $\boldsymbol{C = \mathbf { 5 }}$ & $\boldsymbol{C = \mathbf { 1 0 }}$ & $\boldsymbol{C = 3 0}$ & $\boldsymbol{C}=\mathbf{5 0}$ \\
\hline 15 & 8.59 & 10.01 & 11.06 & 12.45 & 14.38 & 17.50 & 18.95 \\
10 & 10.24 & 12.19 & 13.63 & 15.53 & 18.19 & 22.47 & 24.48 \\
15 & 11.34 & 13.58 & 15.22 & 17.40 & 20.45 & 25.35 & 27.65 \\
20 & 12.19 & 14.63 & 16.43 & 18.81 & 22.13 & 27.49 & 29.99 \\
25 & 12.90 & 15.50 & 17.42 & 19.96 & 23.50 & 29.21 & 31.89 \\
30 & 13.51 & 16.25 & 18.27 & 20.94 & 24.67 & 30.68 & 33.50 \\
35 & 14.04 & 16.90 & 19.01 & 21.80 & 25.69 & 31.96 & 34.90 \\
40 & 14.52 & 17.49 & 19.68 & 22.57 & 26.60 & 33.11 & 36.15 \\
45 & 14.96 & 18.02 & 20.28 & 23.26 & 27.43 & 34.15 & 37.29 \\
50 & 15.36 & 18.51 & 20.84 & 23.90 & 28.19 & 35.10 & 38.33 \\
55 & 15.74 & 18.97 & 21.35 & 24.50 & 28.89 & 35.98 & 39.29 \\
60 & 16.09 & 19.39 & 21.83 & 25.05 & 29.54 & 36.80 & 40.19 \\
65 & 16.42 & 19.79 & 22.28 & 25.57 & 30.16 & 37.56 & 41.03 \\
70 & 16.73 & 20.17 & 22.70 & 26.06 & 30.74 & 38.29 & 41.82 \\
75 & 17.02 & 20.52 & 23.11 & 26.52 & 31.29 & 38.97 & 42.57 \\
\hline
\end{tabular}

Then, based on the IDF curves forecast for 2050, generalized short duration rainfall models for Wroctaw were developed (with the example duration $t=75 \mathrm{~min}$ ), as reliable for the future hydrodynamic modelling of stormwater drainage system overloads. Table 4 presents the stages of creating the Euler type II model-with the example frequency of occurrence $C=10$ years and duration $t=75 \mathrm{~min}$, for the current form of the model for 2020 and for the generalized, detailed form (with the intensity peak shifted) forecast for 2050 .

Table 4. Stages of creating Euler type II model for current form of the model for 2020 and for the detailed form forecast for 2050 - for the example occurrence frequency $C=10$ years and duration $t=75 \mathrm{~min}$ (the highest interval intensities are bolded).

\begin{tabular}{|c|c|c|c|c|c|c|c|c|c|}
\hline \multicolumn{5}{|c|}{ Current Rainfall Model for 2020} & \multicolumn{5}{|c|}{ Detailed Euler Type II Model Forecasted for 2050} \\
\hline $\begin{array}{c}t, \\
\min \end{array}$ & $\begin{array}{c}h, \\
\mathrm{~mm}\end{array}$ & $\begin{array}{l}\Delta h \\
\mathrm{~mm}\end{array}$ & $\begin{array}{c}I, \\
\mathrm{~mm} / \mathrm{h}\end{array}$ & $\begin{array}{l}\text { Euler Type } \\
\text { II Model }\end{array}$ & $\begin{array}{c}t \\
\min \end{array}$ & $\begin{array}{c}h, \\
\mathrm{~mm}\end{array}$ & $\begin{array}{c}\Delta h, \\
\mathrm{~mm}\end{array}$ & $\begin{array}{c}I, \\
\mathrm{~mm} / \mathrm{h}\end{array}$ & $\begin{array}{c}\text { Euler Type } \\
\text { II Model }\end{array}$ \\
\hline 5 & 13.56 & 13.56 & 162.72 & 18.36 & 5 & 14.38 & 14.38 & 172.56 & 27.12 \\
\hline 10 & 18.41 & 4.85 & 58.20 & 22.80 & 10 & 18.19 & 3.81 & 45.72 & 45.72 \\
\hline 15 & 20.99 & 2.58 & 30.96 & 30.96 & 15 & 20.45 & 2.26 & 27.12 & 172.56 \\
\hline 20 & 22.89 & 1.90 & 22.80 & 58.20 & 20 & 22.13 & 1.68 & 20.16 & 20.16 \\
\hline 25 & 24.42 & 1.53 & 18.36 & 162.72 & 25 & 23.50 & 1.37 & 16.44 & 16.44 \\
\hline 30 & 25.72 & 1.30 & 15.60 & 15.60 & 30 & 24.67 & 1.17 & 14.04 & 14.04 \\
\hline 35 & 26.86 & 1.14 & 13.68 & 13.68 & 35 & 25.69 & 1.02 & 12.24 & 12.24 \\
\hline 40 & 27.88 & 1.02 & 12.24 & 12.24 & 40 & 26.60 & 0.91 & 10.92 & 10.92 \\
\hline 45 & 28.80 & 0.92 & 11.04 & 11.04 & 45 & 27.43 & 0.83 & 9.96 & 9.96 \\
\hline 50 & 29.65 & 0.85 & 10.2 & 10.2 & 50 & 28.19 & 0.76 & 9.12 & 9.12 \\
\hline 55 & 30.43 & 0.78 & 9.36 & 9.36 & 55 & 28.89 & 0.70 & 8.40 & 8.40 \\
\hline 60 & 31.17 & 0.74 & 8.88 & 8.88 & 60 & 29.54 & 0.65 & 7.80 & 7.80 \\
\hline 65 & 31.85 & 0.68 & 8.16 & 8.16 & 65 & 30.16 & 0.62 & 7.44 & 7.44 \\
\hline 70 & 32.50 & 0.65 & 7.80 & 7.80 & 70 & 30.74 & 0.58 & 6.96 & 6.96 \\
\hline 75 & 33.11 & 0.61 & 7.32 & 7.32 & 75 & 31.29 & 0.55 & 6.60 & 6.60 \\
\hline
\end{tabular}

Based on the predictive model (4), the maximum rainfall amounts were calculated in 5-min intervals. These amounts were used to calculate interval intensities $(I)$. In the case of the Euler type II model, the highest interval rainfall intensity occurs at the end of $1 / 3$ of the rainfall duration. To this interval are attached on the left side of the time axis the next intervals, with lower intensities, until the time moment $t=0$ is reached. Subsequent intervals occur on the time axis on the right side in relation to the peak, and fill the period to the end of the model rainfall. In the detailed form of the Euler model for 2050, the maximum interval rainfall intensity occurs at the end of $1 / 5$ of the rainfall duration. 
Figure 6 illustrates the example of the generalized short duration rainfall models, with duration $t=75 \mathrm{~min}$ and occurrence frequency $C \in\{1,2,3,5,10,30,50\}$ years (according to the requirements of standard EN 752: 2017). The graphs also show the current Euler type II model determined for 2020 as the background.
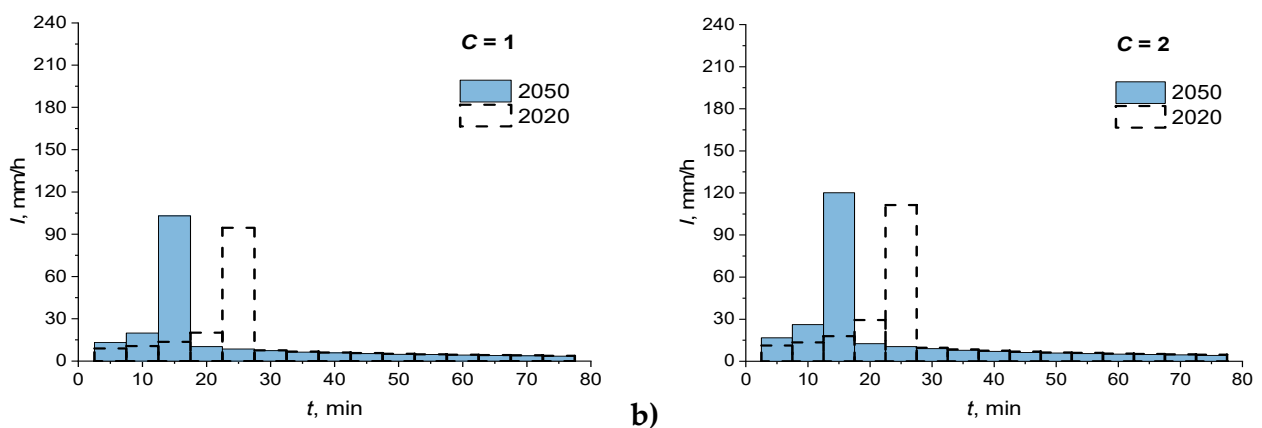

a)

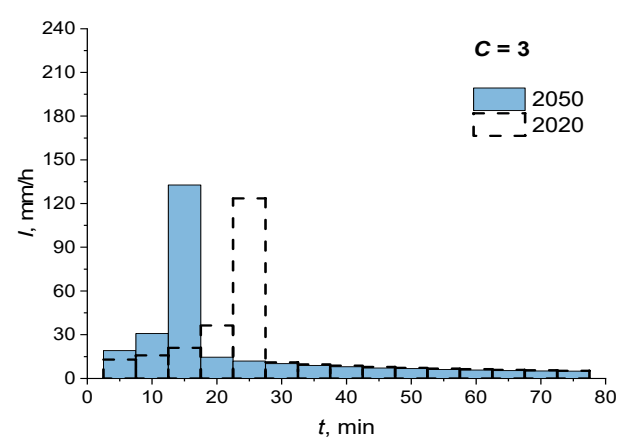

c)

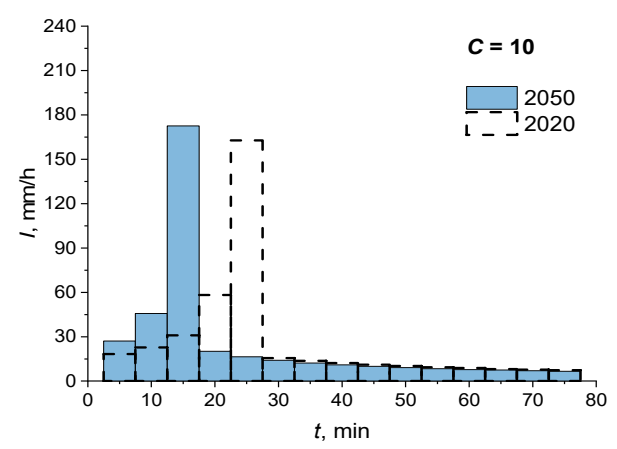

b)

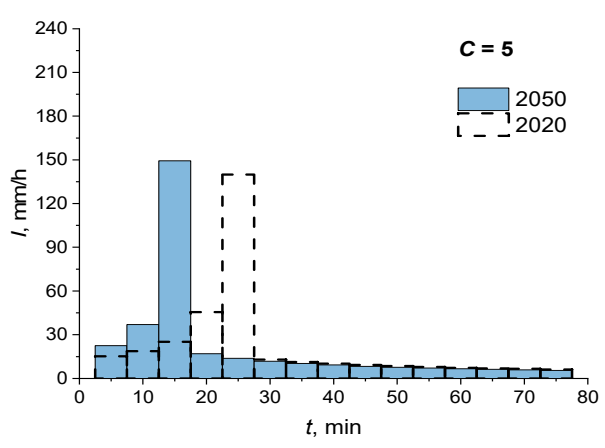

d)

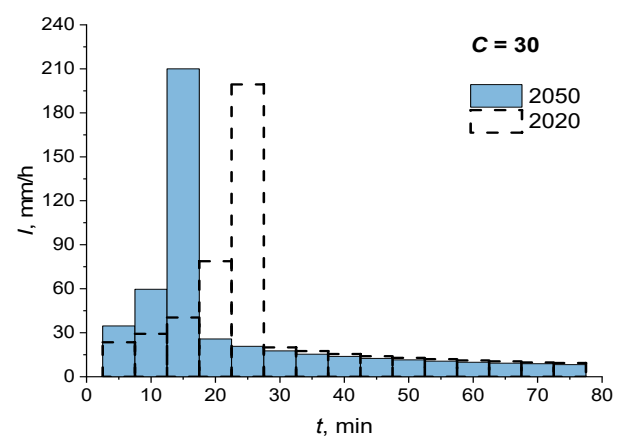

g)

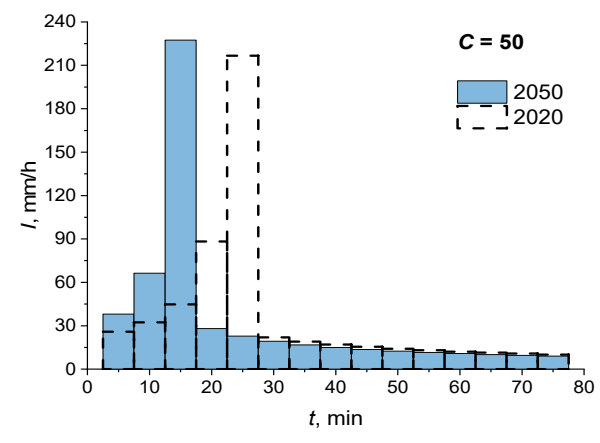

Figure 6. Examples of the generalized short duration precipitation models with duration $t=75 \mathrm{~min}$ developed for 2050 (blue bars) against the background of the current Euler type II model for 2020 (dashed line), for occurrence frequency (a) $C=1$ (b) $C=2$ (c) $C=3$ (d) $C=5$ (e) $C=10$ (f) $C=30$ (g) $C=50$ years for modelling overloads of the stormwater drainage system in Wrocław, according to the requirements of standard EN 752:2017. 
The graphs (Figure 6) present differences in the maximum precipitation interval intensity peaks $(\Delta t=5 \mathrm{~min}$-clearly higher for the generalized models forecast for 2050 in comparison to standard Euler type II models for 2020. In addition, there are significant differences in the distribution of precipitation mass. In the generalized model for 2050, the main mass peak is shifted to the end of the first $1 / 5$ part of the precipitation duration $(t \in(0,0.20] T)$, while in the standard Euler type II model for 2020, the main mass peak occurs at the end of the first $1 / 3$ part of the duration $(t \in(0,0.33] T)$. In both models, approx. $\frac{3}{4}$ of the precipitation mass is concentrated within the range $t \in(0,0.33]$ T The remaining approx. $\frac{1}{4}$ of mass is within the range $t \in(0.33, T)$. After exceeding $t=0.33 T$, differences in mass distribution in both models are very small.

\section{Conclusions}

Model rainfall should reflect the main characteristics of the real precipitation events occurring in a given area. It is therefore advisable to conduct the research on the variability in precipitation intensity in time, based on local databases. Precipitation data with high temporal resolution ( $1 \mathrm{~min}$ ) from the IMGW station and the local network of 11 MPWK rain gauges was selected to investigate the hyetographs' shapes in Wrocław. Selected stations can be considered representative for the hydrological conditions of the central lowland part of Poland. Overall, 126 precipitation events with exceedance frequencies $C(T) \geq 1$ year were selected for statistical analyses, which were genetically grouped (according to duration). Most precipitation events are short-term (59\%), and medium and long duration precipitation events constitute a smaller share (41\%). For qualitative analyses, i.e., precipitation grouping according to the similarity of the hyetographs' shape, three research methodologies were used: the Huff method, cluster analysis by the Ward method and the $k$-means method. These methods, especially the $k$-means method (for $k=4$ according to the Ward method), proved useful for the selection of precipitation events according to the genetic characteristics of precipitation. For the quantitative assessment of the similarity of the local hyetographs' shapes, three indicators were used to characterize: location of the maximum amount peak, mass distribution and the unevenness of precipitation intensity in time. The comparative analysis included the verification of the shapes of the Euler type II model and its generalization for the investigated stations in Wrocław.

To sum up, the paper presents the principles of creating generalized local short-term precipitation models. For practical reasons, precipitation events with exceedance frequency $C(t) \geq 1$ year were analyzed as useful for designing and modelling the reliability of operation of drainage systems of urban areas (according to EN 752:2017). The example of precipitation events measured in Wroclaw demonstrated significant differences in the local hyetographs' shape of a short-term precipitation events compared to the previously used Euler type II model. Based on this, a generalized short duration precipitation model for Wrocław was proposed, with a numerical example for practical applications-for the perspective of 2050. It should be noted here that the developed precipitation model is appropriate to describe the precipitation for the analyzed measuring station in Wrocław. The research was based on the predictive model for the maximum rainfall amount, developed based on rainfall data from the Wrocław station, with the use of the peak over threshold (POT) method and generalized exponential distribution (GED).

The performed research allows us to formulate the following final conclusions, with scientific and practical relevance:

1. The largest precipitation sample above the threshold amount-for occurrence frequency $C(T) \geq 1$ year are short duration precipitation events in Wroclaw, for which the main mass, i.e., approx. 3/4, is concentrated in the first $1 / 3$ part of their duration. This temporal distribution of precipitation is characteristic for precipitation events with durations $T<150 \mathrm{~min}$.

2. In the verified Euler type II model, the location of the peak of maximum interval rainfall amount shifts from $1 / 3$ to $1 / 5$ of the precipitation duration $(T)$. However, the main precipitation mass remains at $1 / 3 T$. This means that the idea of creating precipitation models-from IDF curves-can 
be considered as positively verified on the investigated precipitation from (lowland) stations in Wrocław.

3. A generalized short duration precipitation model — forecast for 2050 — was established for Wrocław, with the maximum interval intensity peak located in the first $1 / 5$ part of the precipitation duration and with its greater value. The generalized model can be considered reliable for the hydrodynamic modelling of stormwater drainage system overloads. A larger peak of interval rainfall intensity may result in increasing the probability of flooding occurrence from sewers and therefore in reducing the sewage systems reliability in the future.

4. The presented research results should be verified on a larger number of IMGW stations and the local precipitation monitoring networks to confirm the investigated dependencies in Wrocław in other regions of Poland.

Supplementary Materials: The following are available online at http://www.mdpi.com/2073-4433/11/6/663/s1, Table S1: Sewer systems design criteria for sewer flooding threats according to EN 752 from 2017.

Author Contributions: Conceptualization, K.W. and A.K.; methodology, K.W. and A.K.; formal analysis, A.K.; investigation, K.W.; resources, K.W.; writing —original draft preparation, K.W. and A.K.; writing-review and editing, K.W.; visualization, K.W.; supervision, A.K.; funding acquisition, A.K. All authors have read and agreed to the published version of the manuscript.

Funding: This research received no external funding.

Conflicts of Interest: The authors declare no conflict of interest.

\section{References}

1. Kaźmierczak, B. Prognozy Zmian Maksymalnych Wysokości Opadów Deszczowych We Wrocławiu [Prediction of Changes in Maximum Rainfall Amounts in Wrocław]; Oficyna Wydawnicza Politechniki Wrocławskiej: Wrocław, Poland, 2019.

2. IPCC. Climate Change: Impacts, Adaptation, and Vulnerability. Contribution of Working Group II to the Fifth Assessment Report of the Intergovernmental Panel on Climate Change; Cambridge University Press: New York, NY, USA, 2014.

3. Landerink, G.; Van Meijgaard, E. Increase in hourly precipitation extremes beyond expectations from temperature changes. Nat. Geosci. 2008, 1, 511-514. [CrossRef]

4. Rupa, C.R.; Mujumdar, P.P. Chapter 3-Modeling High-Intensity Precipitation for Urban Hydrologic Designs. In Trends and Changes in Hydroclimatic Variables; Elsevier: Amsterdam, The Netherlands, 2019; pp. 149-197.

5. Wartalska, K.E.; Kotowski, A. Metodyka Tworzenia Wzorców Opadów Do Modelowania Odwodnień Terenów [Methodology for Creating Precipitation Patterns for Modeling of Land Drainage]; Oficyna Wydawnicza Politechniki Wrocławskiej: Wrocław, Poland, 2020.

6. Larsen, A.N.; Gregorsen, I.B.; Christensen, O.B.; Linde, J.J.; Mikkelsen, P.S. Potential future increase in extreme one-hour precipitation events over Europe due to climate change. Water Sci. Technol. 2009, 60, 2205-2216. [CrossRef] [PubMed]

7. Onof, C.; Arnbjerg-Nielsen, K. Quantification of anticipated future changes in high resolution design rainfall for urban areas. Atmos. Res. 2009, 92, 350-363. [CrossRef]

8. Blöschl, G.; Hall, J.; Parajka, J.; Perdigão, R.A.; Merz, B.; Arheimer, B.; Aronica, G.T.; Bilibashi, A.; Bonacci, O.; Borga, M.; et al. Changing climate shifts timing of European floods. Science 2017, 357, 588-590. [CrossRef] [PubMed]

9. Willems, P. Revision of urban drainage design rules based on extrapolation of design rainfall statistics. In Proceedings of the 12th Int. Conference on Urban Drainage, Porto Alegre, Brazil, 11-16 September 2011.

10. Kaźmierczak, B.; Kotowski, A. The influence of precipitation intensity growth on the urban drainage systems designing. Theor. Appl. Climatol. 2014, 118, 285-296. [CrossRef]

11. Nowakowska, M.; Wartalska, K.; Kaźmierczak, B.; Kotowski, A. Verification of the Stormwater Drainage System Overloads in Wrocław for an Assessment of Climate Change Effects. Period. Polytech. Civ. Eng. 2019, 63, 641-646. [CrossRef]

12. Chow, V.T.; Maidment, D.R.; Mays, L.W. Applied Hydrology; McGraw-Hill: New York, NY, USA, 1988. 
13. Veneziano, D.; Villani, P. Best linear unbiased design hyetograph. Water Resour. Res. 1999, 35, $2725-2738$. [CrossRef]

14. Lin, G.F.; Chen, L.H.; Kao, S.C. Development of regional design hyetographs. Hydrol. Process. 2005, 19, 937-946. [CrossRef]

15. Cazanescu, S.; Cazanescu, R.A. New hydrological approach for environmental protection and floods management. Bull. UASVM Agric. 2009, 66, 63-70.

16. Keifer, C.J.; Chu, H.H. Synthetic storm pattern for drainage design. J. Hydraul. Eng. Div. 1957, 83, 1-25.

17. Huff, F.A. Time distribution of rainfall in heavy storms. Water Resour. Res. 1967, 3, 1007-1019. [CrossRef]

18. Pani, E.A.; Haragan, D.R. A comparison of Texas and Illinois temporal rainfall distributions. In Proceedings of the Fourth Conference on Hydrometeorology, Reno, NV, USA, 7-9 October 1981; American Meteorological Society: Boston, MA, USA, 1981; pp. 76-80.

19. Bonta, J.V.; Rao, A.R. Factors affecting development of Huff curves. Trans. ASAE 1987, 30, $1689-1693$. [CrossRef]

20. Terranova, O.G.; Iaquinta, P. Temporal properties of rainfall events in Calabria (southern Italy). Nat. Hazard. Earth Syst. 2011, 11, 751-757. [CrossRef]

21. Pan, C.; Wang, X.; Liu, L.; Huang, H.; Wang, D. Improvement to the Huff Curve for Design Storms and Urban Flooding Simulations in Guangzhou, China. Water 2017, 9, 411. [CrossRef]

22. Bonta, J.V. Development and utility of Huff curves for disaggregating precipitation amounts. Appl. Eng. Agric. 2004, 20, 641-652. [CrossRef]

23. Wartalska, K.; Kaźmierczak, B.; Nowakowska, M.; Kotowski, A. Analysis of Hyetographs for Drainage System Modeling. Water 2020, 12, 149. [CrossRef]

24. Kaźmierczak, B.; Kotowski, A. Depth-duration-frequency rainfall model for dimensioning and modelling of Wrocław drainage systems. Environ. Prot. Eng. 2012, 38, 127-138. [CrossRef]

25. Kotowski, A.; Kaźmierczak, B. Probabilistic models of maximum precipitation for designing sewerage. J. Hydrometeorol. 2013, 14, 1958-1965. [CrossRef]

26. Kaźmierczak, B.; KOTOWSKI, A. The suitability assessment of a generalized exponential distribution for the description of maximum precipitation amounts. J. Hydrol. 2015, 525, 345-351. [CrossRef]

27. D'agostino, R.; Stephens, M.A. Goodness of Fit Techniques; Marcel Dekker: New York, NY, USA, 1986.

28. Laio, F.; Di Baldassarre, G.; Montanari, A. Model selection techniques for the frequency analysis of hydrological extremes. Water Resour. Res. 2009, 45. [CrossRef]

29. Zucchini, W.Z. An introduction to model selection. J. Math. Psychol. 2000, 44, 41-51. [CrossRef] [PubMed]

30. Hamed, K.H. Trend detection in hydrologic data: The Mann-Kendall trend test under the scaling hypothesis. J. Hydrol. 2008, 349, 350-363. [CrossRef]

31. Machiwal, D.; Jha, M.K. Time series analysis of hydrologic data for water resources planning and management: A review. J. Hydrol. Hydromech. 2006, 54, 237-257. 